\title{
A Literature Review on the Connection between Stress and Self-Esteem
}

\author{
Michael Galanakis', Anastasia Palaiologou², Georgia Patsi², Ioanna-Maria Velegraki², \\ Christina Darviri2* \\ ${ }^{1}$ Panteion University of Social and Political Sciences, Athens, Greece \\ ${ }^{2}$ Postgraduate Course Science of Stress and Health Promotion, School of Medicine, University of Athens, \\ Athens, Greece \\ Email: *cdarviri@yahoo.com
}

Received 12 December 2015; accepted 13 May 2016; published 16 May 2016

Copyright (C) 2016 by authors and Scientific Research Publishing Inc.

This work is licensed under the Creative Commons Attribution International License (CC BY).

http://creativecommons.org/licenses/by/4.0/

c) (i) Open Access

\begin{abstract}
The current study investigates how stress and self-esteem interact in a wide range of levels. Studying the recent literature of the last five years, we understood that the findings indicated that self-esteem affected stress and it was affected from stress. This interaction takes place in different levels, including personal, psychological and professional parameters. These findings point out the importance of this interaction and the necessity of use of some stress management techniques which can not only reduce stress, but also improve self-esteem. As a result, the purpose of this literature review is to examine the connection between stress and self-esteem and to use this knowledge in order to reduce stress, improve self-esteem and as a result eliminate psychological disorders and ameliorate the quality of people's life.
\end{abstract}

\section{Keywords}

Self-Esteem, Psychological Disorders, Stress Management, Quality of Life

\section{Introduction}

People in today's society suffer from stress in a wide range of situations. Stress is present in people's lives and is believed to be the cause of psychopathologies, diseases and inability to adapt to any given environment or work (Feldman et al., 2008). Stress is considered a complex defensive-balancing mechanism of the body that develops in two stages: during the first stage, individuals assess the stressor and the demands stemming from it, and during the second stage, they evaluate whether or not they have enough resources to meet the stressor demands. The

${ }^{*}$ Corresponding author. 
latter stage draws attention to the individual's subjective assessment of the stressor, which conditions their reaction to it. Different people may react differently to the same stressor. The stress response refers to body reactions, which can either be physiological, emotional or behavioral reactions to stimuli that cause stress.

Self-esteem is a psychological trait related to a person's image of self-value and self confidence in total aspects of human activity (Rosenberg, 1965). Studies all over the world have associated self-esteem with human health and psychological well-being. This effect may be interpetated through the scope of resources increase and active coping against life's problems. Moreover there seems to be a strong antistress impact on self-esteem regardless of the circumstances (Pruessner, Hellhammer, \& Kirschbaum, 1999). High self-esteem is considered a fundamental aspect of personal well-being, happiness and adjustment (Brown, 1993). Individuals with higher self-esteem are more satisfied with their lives, have fewer interpersonal problems, achieve at a higher and more consistent level, and are less susceptible to psychological problems (e.g., anxiety and depression) and physical illness (Brown, 1993) than those with lower self-esteem.

Self-esteem refers to the positive or negative way people feel about themselves as a whole, which is also often called global self-esteem or global self-worth (Brown, Dutton, \& Cook, 2001).

Many studies show the relationship of stress and self-esteem at multiple levels. Self-esteem is included in psychological resources that help people manage stressful events and their responses to them (Taylor et al., 2010). Self-esteem affects people's reaction to stressful events and in addition the way individuals cope with stress. At the same time, stressful events negatively affect self-esteem, which is a psychological resource against psychological disorders. The purpose of this literature review is to examine the connection between stress and self-esteem and to use this knowledge in order to reduce stress, improve self-esteem and as a result eliminate psychological disorders and ameliorate the quality of people's life.

\section{Stress}

Stress is defined by Professor G. Chrousos as "the threat or perceived threat condition of homeostasis, which is established through a complex web of behavioral and physiological responses of the body to adapt” (Chrousos, 2009) and by Lazarus R.S and Folkman S. as "the result of interaction between the individual and the environment. When persons feel that they cannot cope with the number of abilities and skills in environmental requirements, is experiencing stress” (Berjot \& Gillet, 2011). In the term of stress we can attribute a negative (distress) and a positive dimension (eustress). In particular healthy homeostasis called eustasis, whereas poor adaptation response to stress, leading to defective homeostasis called allostasis.

Stress system located in the hypothalamus and brain stem. The procedure is the following. The paraventricular nucleus of the hypothalamus (PVN) containing neurons who secrete corticotropin-releasing hormone (CRH) and arginine-vasopressin peptide (AVP) and the locus ceruleus in the brain bridge produces the neurotransmitter norepinephrine (LC/NE). The two elements are connected together by turning one another. Each of the two central elements of the stress system affects peripheral organs. Thus, in the paraventricular nucleus of the hypothalamus starts the hypothalamic pituitary adrenal (HPA) pathway and from the system LC/NE starts the way of the sympathetic/adrenomyelodus system (Chrousos, 2009).

The paraventricular nucleus of the hypothalamus produces $\mathrm{CRH}$ and AVP that trigger the production of ACTH in the anterior pituitary. The ACTH is secreted in the blood and stimulates the adrenal cortex to produce glucocorticoids, such as cortisol. Cortisol is a catabolic hormone that stimulates metabolic mechanisms throughout the body to produce energy in order to cope with stressful situations (Chrousos, 2009).

According to Lazarus R.S. and Folkman S. the estimation of a stressful event and in continue the evaluation as a threat or not by the individual, are included in the psychological approach of stress. The person considers a stressful event as a threat, when his ability to deal with it, is assessed as less than the requirements of the event. Perceived stress is defined especially after having studied the interaction between the individual and the environment, psychological stress include the interpretation of the adequacy of management methods and based on the notion that stress results from the subjective assessment of the individual in his relation with the environment (Lazarus \& Folkman, 1984).

This relationship between the individual and the environment created through two major phases 1) cognitive assessment, primary and secondary (cognitive appraisal) and 2) coping. During the primary assessment process the person recognizes the stimulus of the environment as stressful or not. If assessed as stressful for the individual, then it is estimated as a threat, as a loss or as a challenge. In the secondary appraisal, the individual makes an assessment of the physical, social, psychological and material resources which are available in order to be 
capable to face the stressful stimulus. Also refers to the cognitive and behavioral efforts of the individual to reduce the requirements of the stressful stimulus. Thus, stress on the one hand, is a defensive-balancing mechanism of the body to cope and survive in stressful stimuli but on the other hand, is differently perceived by individuals (Lazarus \& Folkman, 1984).

\section{Self-Esteem}

The concept of self-esteem has elicited a large body of theoretical accounts and empirical research (Baumeister, 1998). Historically, the first influential definition of self-esteem dates back to James 1890 (James, 1890) who considered self-esteem to be the ratio of success and pretensions in important life domains. Whereas James focused to a stronger degree on the individual processes that form self-esteem later symbolic interactionism approaches stressed the social influences on self-esteem (Goffman, 1959; Mead, 1934). For instance, in his conception of the looking-glass self (Cooley, 1902) hypothesized that self-views are based upon information gathered from explicit or implicit feedback from others.

More recent definitions of self-esteem emphasize the fact that self-esteem should be distinguished from other components of the self-concept (such as self-knowledge and self-efficacy), insofar as self-esteem represents the affective, or evaluative, component of the self-concept; it signifies how people feel about themselves (Leary \& Baumeister, 2000). This affective self-evaluation is subjective at its core and is not based on specific behaviors (Robins, Hendin, \& Trzesniewski, 2001).

According to Rosenberg, high self-esteem expresses the feeling that one is good enough and self-esteem is defined as a favourable or unfavourable attitude toward the self (Rosenberg \& Pearlin, 1978). What is more, self-esteem is generally used to describe a person's overall sense of self-worth and can involve a variety of beliefs about the self. High self-esteem is considered a fundamental aspect of personal well-being, happiness and adjustment. Individuals with higher self-esteem are more satisfied with their lives, have fewer interpersonal problems, achieve at a higher and more consistent level, and are less susceptible to psychological problems (e.g., anxiety and depression) and physical illness than those with lower self-esteem. Also, self-esteem refers to the positive or negative way people feel about themselves as a whole, which is also often called global self-esteem or global self worth.

Global self-esteem is defined as the overall positive or negative attitude towards the self (Rosenberg, 1965). High global self-esteem has been found to be related to positive self-evaluations, characterized by having an accepting attitude towards one's self, and has been identified as a crucial factor in preventing stress and mental health problems such as depression (Avison \& McAlpine, 1992). In contrast, low global self-esteem has been found to be associated with negative self-evaluations, characterized by self-doubts and self-rejection (Baumeister, Campbell, Krueger, \& Vohs, 2003) and has been shown to predict stress symptoms and ill-health (Birndorf, Ryan, Auinger, \& Aten, 2005).

\section{Stress and Self-Esteem}

\subsection{Self-Esteem and Cortisol Secretion}

Reviewing the current literature, we notice that the stress is associated with self-esteem in multiple ways. Stressful events affect self-esteem and self-esteem in turn affects the way people react to stress and cope with it. According to the survey of Sarah Yu-Tsu Liu (Liu, Wrosch, Miller, \& Pruessner, 2014) self-esteem can decline in older adulthood. This can be attributed to higher levels of diurnal cortisol secretion and disturbances of HPA axis. In turn the decline of self-esteem in older adulthood results in lower stress coping ability due to the lack of personal psychological and emotional resources. Thus with the passing of age a person is more likely to experience lower self-esteem levels leading to increased risk of distress and depression. The opposite is also true, meaning that the establishment of higher levels of self-esteem in older populations can protect against distress and depression negative results. Self-esteem holds a cause-effect role regarding psychological and physical health and can definitely be connected to life satisfaction and quality of life.

\subsection{Self-Esteem and Early Life Stress}

According to Suzuki and Tomoda early life stress in children, because of lack of care and maltreatment, reduces 
child's self-esteem and safely bond that it has with his parents and is likely for child to have depression in the future (Suzuki \& Tomoda, 2015). In this study, stressful events are considered maltreatment, parental illness and death and sociopathic behaviors. All these facts reinforce avoidant and ambivalent behavior as well as insecure. As a result, children which have experienced these stressful events have low self-esteem and are possible to have depressive symptoms (Suzuki \& Tomoda, 2015). Also, people with low self-esteem and depression react with more stress in several stressful situations, secretion of cortisol in their blood is higher and their hippocampal volume is reduced (Orth, Robins, Widaman, \& Conger, 2014).

Rhee et al. (Rhee, Pan, Norman, Crow, \& Boutelle, 2013) find in their study that parents may play an important role in preventing emotional eating in children by promoting self-efficacy (belief or confidence in one's ability) to eat healthily during stressful situations. Parenting styles, parental response to child emotion, and family emotional responsiveness are related to child emotional eating. The results suggest that firm/controlling parenting behaviors can have negative consequences for child eating self-efficacy while more accepting parenting behaviors may help children utilize healthier eating practices when feeling stressed. This study suggests that controlling parenting behaviors decrease child self-efficacy and self-esteem to engage in healthy eating behaviors during difficult emotional situations (Rhee, Pan, Norman, Crow, \& Boutelle, 2013).

\subsection{Stress, Self-Esteem and Depression}

According to Fernández-González et al., self-esteem seems to be associated with stressors that have to do with emotion (Fernández-González, González-Hernández, \& Trianes-Torres, 2015). Lots of researches have been shown that low self-esteem and stress are associated with mood disorders and depression. In particular, in a study of Jocelyn Smith Carter and Judy Garber, low self-esteem and low self-worth are associated with stress and depression. Both of them, constitute risk factors for appearance of depression, as people cannot manage and cope with the stressful life events (Carter \& Garber, 2011). Furthermore, in another study of Ali Al Nima et al., successfully coping with anxiety, depressiveness, and stressful situations may contribute to high levels of self-esteem and self-confidence. The results in the present study show that anxiety partially mediated the effects of both stress and self-esteem on depression (Nima, Rosenberg, Archer, \& Garcia, 2013).

The study suggests that anxiety contributes directly to explaining the variance in depression while stress and self-esteem might contribute directly to explaining the variance in depression and indirectly by increasing feelings of anxiety. Indeed, individuals who experience stress over a long period of time are susceptible to increased anxiety and depression and high self-esteem seems to buffer against anxiety and depression. So, self-esteem contribute only indirectly via the experienced level of stress to explain the variation in depression, for example, stress affects depression on the basis of 'its own power' and explains much more of the variation in depressive experiences than self-esteem (Nima, Rosenberg, Archer, \& Garcia, 2013).

Also, low-self-esteem individuals are especially vulnerable to those unstable and negative circumstances because their feelings of self-worth tend to drop under failure, they are more concerned about self-protection in stressful situations, and they are more likely to have depressive attributions in response to negative events. They also have a tendency to overgeneralize the negative consequences of a stressful situation and find it difficult to repair their negative moods. The effects of these maladaptive responses to stressful situations can be aggravated when stressors are perceived as threatening and uncontrollable, first, because they can further impede an individual's ability to cope successfully and, second, because those perceptions only verify the initial negative biases (Nima, Rosenberg, Archer, \& Garcia, 2013).

In line with the contextual model of stress and coping, Sharon C. Lee-Flynn et al. propose that self-esteem is associated with adaptation to stress by changing the impact of stress appraisals on adaptational outcomes. They found a significant interaction between self-esteem and daily stressor appraisals. More specifically, self-esteem attenuated the detrimental effect of negative stressor appraisals on daily negative effect. When participants appraised their most important stressful event of the day as more threatening, those with high self-esteem tended to experience lower subsequent negative affect than those with low self-esteem (Lee-Flynn et al., 2015). Finally stress negatively affects self-esteem, regardless of whether a person has depression. Conversely, low self-esteem makes individual prone to in experiencing stressful events through an indirect effect via depression (Orth \& Luciano, 2015).

\subsection{Self-Esteem and Academic Stress}

Students with high self-esteem seem to be less stressed than those who have low self-esteem and have high 
stress (Reilly et al., 2014). Karin Schraml et al. (Schramla et al., 2011) examined three major groups of stressrelated factors, namely, adolescent subjective psychosocial conditions, lifestyle, and self-esteem. The results of this study confirm that a substantial number of high school students, especially females, feel stressed and psychologically burdened. Furthermore, it is showed that highly stressed individuals, are more likely to feel worse about themselves, base their self-esteem on performance, and have more sleep problems as compared to non-stressed individuals. Compared to male students, the females not only reported significantly more stress symptoms, lower global self-esteem, and higher performance-based self-esteem, but also reported perceiving higher demands and having more difficulties sleeping. It is found also (Kandemir, Iihan, Ozpolat, \& Palanci, 2014) that academic procrastination is related to self-esteem, academic self-efficacy, active planning coping with stress skills and bio-chemical avoidant coping with stress.

Finally, the transition to college has often been treated as a period that creates considerable stress in the lives of students, increases their distress and lowers their self-esteem (Besser \& Zeigler-Hill, 2012). Distress symptoms are prevalent during this key transitional period as students adjust to the new demands that are placed on them during their freshman year. Thus, stressors that are related to life-transitions, appear to have the capacity to erode self-esteem. Positive personality features had significant positive associations with self-esteem levels and negative associations with psychological distress symptoms and functional impairment. In the process of a prolonged period of stress positive personality features may protect students from psychological distress which may lead to greater distress, more functional impairment, and lower self-esteem. These facts are consistent with the "scar model" of self-esteem, which suggests that the commonly observed association between self-esteem and psychological distress is due to low self-esteem sometimes being an outcome of psychological distress rather than a cause (Besser \& Zeigler-Hill, 2012).

\subsection{Self-Esteem and Burnout}

Self-esteem resulting from an individual's job performance, can work as an in-dependent stressor or it can increase the negative effects of stressful events of his personal and professional life leading to burnout. Performance based self-esteem mediated partially between the stressors and burnout and it is the strongest predictor of burnout over time, followed by private life stressors. Women experienced more work stress than did men. Men had stronger associations between work stressors and burnout, while women had stronger associations between performance based self-esteem and burnout (Blom, 2012).

Also, stress is negatively correlated with self-esteem and self-efficacy. According to Reilly et al., educators and teachers with high self-esteem and high self-efficacy have lower stress at their work. Teacher stress may be defined as the experience by a teacher of unpleasant, negative emotions, such as anger, anxiety, tension, frustration or depression which results from the occupation demands of teaching, as well as the degree of mismatch between these demands and an individual's ability to cope with them. Stress among teachers is a widespread, and perhaps increasing, problem and this study highlights the important influence of perceived stress on teachers' job satisfaction. Importantly, perceived stress is likely to be a modifiable variable that could be effectively targeted at an individual and organizational level to improve teachers' work satisfaction for example, stress management, training, counseling, organizational restructuring, and job redesign (Blom, 2012).

\section{Techniques of Stress Management and Self-Esteem}

Several studies show that the stress management techniques in addition to reducing stress, improve self-esteem. Firstly, transcendental meditation reduces stress and improves attention resulting in enhanced academic performance. Yogic practices like asana, pranayama, vedic chanting, and meditation enhances attention, self-esteem and improves visual and spatial memory. Yoga may improve adjustment among chronically stressed and disadvantaged students by enhancing self-esteem. Stress has an implication for low self-esteem in students, and it was reported that regular practice of Yoga by medical students for a longer period may possibly result in improved management of their daily stress. Several studies have been published analyzing the effect of different aspects of Yoga including cleansing techniques, physical postures, breathing practices, relaxation techniques and meditation on attention, and self-esteem (Sethi, Nagendra, \& Ganpat, 2013).

Meditation helps students improve their self-esteem. Students found Mindfulness Meditation helpful for increasing self-regulation, calming themselves, relieving stress, increasing relaxation, and improving emotional 
coping. In addition, students reported knowing themselves better and increased abilities to pay attention and to control thinking. Meditation can also be taught as a method of self-care as it has been shown to be an effective stress reliever (Caldwell et al., 2010; Wisner, Jones, \& Gwin, 2010).

Moreover, self-enhancing humor (e.g., having a humorous outlook on life) which is utilized to maintain self-esteem and cope with stress. The self-defeating humor style is of particular interest because it was found to have a strong negative correlation with explicit self-esteem and positive correlations with depression, anxiety, and a variety of psychiatric and somatic symptoms suggesting that this humor style tends to be used by individuals experiencing psychological distress (Stieger, Formann, \& Burger, 2011).

Finally, universities may pay particular attention to the distress of students during the initial transition period to college. Students who lack the protective resources provided by positive personality features and experience distress, have an especially strong need for support to increase their self-esteem. Universities can provide to students counseling services and workshops. Further, universities may help transitional students maintain or develop optimism, hope, happiness and heighten their self-esteem since these characteristics may be especially beneficial for first-year college students as they struggle to deal with an array of stressful situations during their adjustment to life as a college student.

\section{Conclusions}

In this literature review, several studies are presented that show the relationship of stress and self-esteem at multiple levels. Initially, at biological level, low self-esteem increases cortisol levels and provokes dysfunction of HPA axis indicating the link with stress. Then, we notice that early stress in life, reduces the self-esteem of children making them vulnerable to develop depression in the future. Moreover, studies show that self-esteem is associated directly and indirectly to the development of depression. Specifically, low self-esteem combined with stress is risk factors for developing depression.

Furthermore, self-esteem plays an important role in stress experienced by students. In particular, students with high self-esteem can efficiently manage stress and therefore have better academic performance. What is more, the self-esteem is related with occupational stress, job performance and job satisfaction. The higher occupational stress workers have the lower self-esteem they have and thus have strong possibility for burnout. Finally, there are many stress management techniques that improve people's self-esteem for example yoga, meditation, humor, mindfulness and counselling.

Therefore, we conclude that techniques of stress management can improve people's self-esteem, which can be as a buffer against psychological disorders plus improving both personal and professional quality of life.

\section{References}

Avison, R., \& McAlpine, D. D. (1992). Gender Differences in Symptoms of Depression among Adolescents. Journal of Health and Social Behavior, 33, 77-96. http://dx.doi.org/10.2307/2137248

Baumeister, R. F. (1998). The Self. In D. T. Gilbert, S. T. Fiske, \& G. Lindzey (Eds.), The Handbook of Social Psychology (Vol. 1, pp. 680-740). Boston, MA: McGraw-Hill.

Baumeister, R. F., Campbell, J. D., Krueger, J. I., \& Vohs, K. D. (2003). Does High Self-Esteem Cause Better Performance, Interpersonal Success, Happiness, or Healthier Lifestyles? Psychological Science in the Public Interest, 4, 1-44. http://dx.doi.org/10.1111/1529-1006.01431

Berjot, S., \& Gillet, N. (2011). Stress and Coping with Discrimination and Stigmatization. Frontiers in Psychology, $2,33$.

Besser, A., \& Zeigler-Hill, V. (2012). Positive Personality Features and Stress among First-Year University Students: Implications for Psychological Distress, Functional Impairment, and Self-Esteem. Self and Identity, 13, 24-44. http://dx.doi.org/10.1080/15298868.2012.736690

Birndorf, S., Ryan, S., Auinger, P., \& Aten, M. (2005). High Self-Esteem among Adolescents: Longitudinal Trends, Sex Differences, and Protective Factors. Journal of Adolescent Health, 37, 194-201. http://dx.doi.org/10.1016/j.jadohealth.2004.08.012

Blom, V. (2012). Contingent Self-Esteem, Stressors and Burnout in Working Women and Men. Work, 43, $123-131$.

Brown, J. D. (1993). Self-Esteem and Self-Evaluations: Feeling is Believing. In J. Suls (Ed.), Psychological Perspectives on the Self (Vol. 4, pp. 27-58). Hillsdale, NJ: Erlbaum Press.

Brown, J. D., Dutton, K. A., \& Cook, K. E. (2001). From the Top down: Self-Esteem and Self-Evaluation. Cognition and Emotion, 15, 615-631. http://dx.doi.org/10.1080/02699930126063 
Caldwell, K., Harrison, M., Adams, M., Quin, R.H., \& Greeson, J. (2010). Developing Mindfulness in College Students through Movement Based Courses: Effects on Self-Regulatory Self-Efficacy, Mood, Stress, and Sleep Quality. Journal of American College Health, 58, 433-442.

Carter, J. S., \& Garber, J. (2011). Predictors of the First Onset of a Major Depressive Episode and Changes in Depressive Symptoms across Adolescence: Stress and Negative Cognitions. Journal of Abnormal Psychology, 120, 779-796. http://dx.doi.org/10.1037/a0025441

Chrousos, G. P. (2009). Stress and Disorders of the Stress System. Nature Reviews Endocrinology, 5, 374-381. http://dx.doi.org/10.1038/nrendo.2009.106

Cooley, C. H. (1902). Human Nature and Social Order. New York, NY: C. Scribner's Son.

Feldman, L., Goncalves, L., Chacón-Puignau, G., Zaragoza, J., Bagés, N., \& Pablo, J. (2008). Relaciones entre estrésacadémico, apoyo social, salud mental y rendimientoacadémicoenestudiantesuniversitariosvenezolanos. Universitas Psychologica, 7, 739-751.

Fernández-González, L., González-Hernández, A., \& Trianes-Torres, M. V. (2015). Relationships between Academic Stress, Social Support, Optimism-Pessimism and Self-Esteem in College Students. Electronic Journal of Research in Educational Psychology, 13, 111-130. http://dx.doi.org/10.14204/ejrep.35.14053

Goffman, E. (1959). The Presentation of Self in Everyday Life. Garden City, NY: Doubleday-Anchor.

James, W. (1890). The Principles of Psychology. New York: Henry Holt and Company the Principles of Psychology. http://dx.doi.org/10.1037/11059-000

Kandemir, M., Iihan, T., Ozpolat, A. R., \& Palanci, M. (2014). Analysis of Academic Self-Efficacy, Self-Esteem and Coping with Stress Skills Predictive Power of Academic Procrastination. Educational Research and Reviews, 9, 146-152. http://dx.doi.org/10.5897/ERR2014.1763

Lazarus, R. S., \& Folkman, S. (1984). Stress, Appraisal and Coping. New York: Springer.

Leary, M. R., \& Baumeister, R. F. (2000). The Nature and Function of Self-Esteem: Sociometer Theory. Advances in Experimental Social Psychology, 32, 1-62. http://dx.doi.org/10.1016/s0065-2601(00)80003-9

Lee-Flynn, S. C., Pomaki, G., DeLongis, A., Biesanz, J. C., \& Puterman, E. (2015). Daily Cognitive Appraisals, Daily Affect, and Long-Term Depressive Symptoms: The Role of Self-Esteem and Self-Concept Clarity in the Stress Process. Personality \& Social Psychology Bulletin, 37, 255-268. http://dx.doi.org/10.1177/0146167210394204

Liu, S. Y., Wrosch, C., Miller, G. E., \& Pruessner, J. C. (2014). Self-Esteem Change and Diurnal Cortisol Secretion in Older Adulthood. Psychoneuroendocrinology, 41, 111-120. http://dx.doi.org/10.1016/j.psyneuen.2013.12.010

Mead, G. H. (1934). Mind, Self, and Society. Chicago, IL: University of Chicago Press.

Nima, A. A., Rosenberg, P., Archer, T., \& Garcia, D (2013). Anxiety, Affect, Self-Esteem, and Stress: Mediation and Moderation Effects on Depression. PLOS ONE, 8, e73265.

http://dx.doi.org/10.1371/annotation/49e2c5c8-e8a8-4011-80fc-02c6724b2acc

Orth, U., \& Luciano, E. C. (2015). Self-Esteem, Narcissism, and Stressful Life Events: Testing for Selection and Socialization. Journal of Personality and Social Psychology, 109, 707-721. http://dx.doi.org/10.1037/pspp0000049

Orth, U., Robins, R. W., Widaman, K. F., \& Conger, R. D. (2014). Is Low Self-Esteem a Risk Factor for Depression? Findings from a Longitudinal Study of Mexican-Origin Youth. Developmental Psychology, 50, 622-633.

http://dx.doi.org/10.1037/a0033817

Pruessner, J. C., Hellhammer, D. H., \& Kirschbaum, C. (1999). Low Self-Esteem, Induced Failure and the Adrenocortical Stress Response. Personality and Individual Differences, 27, 477-489. http://dx.doi.org/10.1016/S0191-8869(98)00256-6

Reilly, E., Dhingra, K., \& Boduszek, D. (2014). Teachers’ Self-Efficacy Beliefs, Self-Esteem, and Job Stress as Determinants of Job Satisfaction. International Journal of Educational Management, 28, 365-378 http://dx.doi.org/10.1108/IJEM-04-2013-0053

Rhee, K. E., Pan, T. Y., Norman, G. J., Crow, S., \& Boutelle, K. (2013). Relationship between Maternal Parenting and Eating Self-Efficacy in Overweight Children When Stressed. Eating and Weight Disorders-Studies on Anorexia, Bulimia and Obesity, 18, 283-288. http://dx.doi.org/10.1007/s40519-013-0043-x

Robins, R. W., Hendin, H. M., \& Trzesniewski, K. H. (2001). Measuring Global Self-Esteem: Construct Validation of a Single-Item Measure and the Rosenberg Self-Esteem Scale. Personality and Social Psychology Bulletin, 27, 151-161. http://dx.doi.org/10.1177/0146167201272002

Rosenberg, M. (1965). Society and the Adolescent Self-Image. Princeton, NJ: Princeton University Press.

Rosenberg, M., \& Pearlin, L. I. (1978). Social Class and Self-Esteem among Children and Adults. American Journal of Sociology, 84, 53-77. http://dx.doi.org/10.1086/226740 
Schramla, K., Perskia, A., Grossia, G., \& Simonsson-Sarnecki, M. (2011). Stress Symptoms among Adolescents: The Role of Subjective Psychosocial Conditions, Lifestyle, and Self-Esteem. Journal of Adolescence, 34, 987-996. http://dx.doi.org/10.1016/j.adolescence.2010.11.010

Sethi, J. K., Nagendra, H. R., \& Ganpat, T. S. (2013). Yoga Improves Attention and Self-Esteem in Underprivileged Girl Student. Journal of Education and Health Promotion, 2, 55. http://dx.doi.org/10.4103/2277-9531.119043

Stieger, S., Formann, A. K., \& Burger, C. (2011). Humor Styles and Their Relationship to Explicit and Implicit Self-Esteem. Personality and Individual Differences, 50, 747-750. http://dx.doi.org/10.1016/j.paid.2010.11.025

Suzuki, H., \& Tomoda, A. (2015). Roles of Attachment and Self-Esteem: Impact of Early Life Stress on Depressive Symptoms among Japanese Institutionalized Children. BMC Psychiatry, 15, 8. http://dx.doi.org/10.1186/s12888-015-0385-1

Taylor, S. E., Seeman, T. E., Eisenberger, N. I., Kozanian, T. A., Moore, A. N., \& Moons, W. G. (2010). Effects of a Supportive or an Unsupportive Audience on Biological and Psychological Responses to Stress. Journal of Personality and Social Psychology, 98, 47-56. http://dx.doi.org/10.1037/a0016563

Wisner, B. L., Jones, B., \& Gwin, D. (2010). School-Based Meditation Practices for Adolescents: A Resource for Strengthening Self-Regulation, Emotional Coping, and Self-Esteem. National Association of Social Workers. Children \& Schools, 32, 150-159. http://dx.doi.org/10.1093/cs/32.3.150 